CORRECTION

\title{
Correction: Clinical features of 2041 human brucellosis cases in China
}

The PLOS ONEStaff

There is an error in affiliation 4 and 5 for authors Shengjie Lai and Hongjie Yu. Affiliation 4 should be: WorldPop, Department of Geography and Environment, University of Southampton, Southampton, UK. Affiliation 5 should be: School of Public Health, Fudan University, Key Laboratory of Public Health Safety, Ministry of Education, Shanghai, China. The publisher apologizes for the error $[\mathrm{s}]$.

\section{Reference}

1. Shi Y, Gao H, Pappas G, Chen Q, Li M, Xu J, et al. (2018) Clinical features of 2041 human brucellosis cases in China. PLoS ONE 13(11): e0205500. https://doi.org/10.1371/journal.pone.0205500 PMID: 30476930

\section{G openaccess}

Citation: The PLOS ONE Staff (2019) Correction: Clinical features of 2041 human brucellosis cases in China. PLoS ONE 14(1): e0211102. https://doi. org/10.1371/journal.pone.0211102

Published: January 16, 2019

Copyright: ๑ 2019 The PLOS ONE Staff. This is an open access article distributed under the terms of the Creative Commons Attribution License, which permits unrestricted use, distribution, and reproduction in any medium, provided the original author and source are credited. 